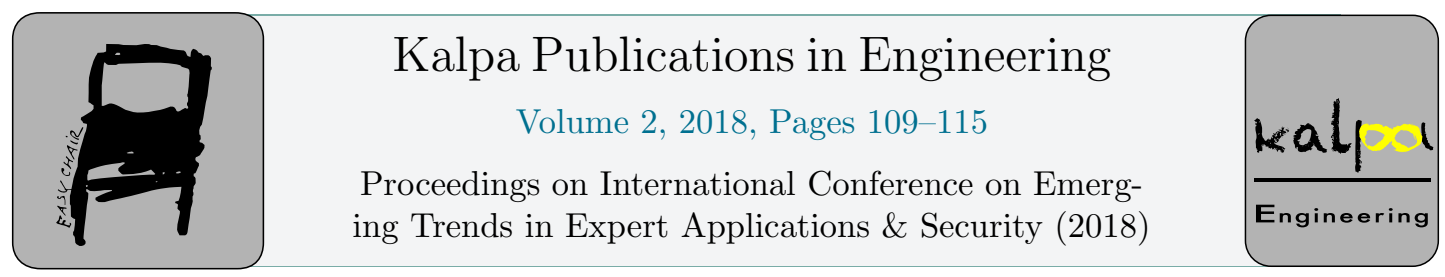

\title{
Design and Implementation of Modified Butterworth Filter for Watermarking
}

\author{
Devendra Kumar Somwanshi ${ }^{1}$, Indu Chhipa ${ }^{2} \&$ Rohita Gupta ${ }^{3}$ \\ ${ }^{1}$ Assistant Professor, ${ }^{2} \mathrm{M}$.Tech Scholar, ${ }^{3}$ Assistant Professor \\ ${ }^{1,2}$ Poornima University, ${ }^{3}$ MAIT \\ Jaipur, India \\ imdev.som@gmail.com, indu.chhipa21@gmail.com, rohita.gupta91@gmail.com
}

\begin{abstract}
In today's world, Internet is becoming more popular for every human. There are various issues and challenges in data security in internet system like the authenticity of content or matter is crucial factor for solving the problem of copying, modifying, and distributing the intellectual properties in an illegal way. Watermarking can resolve the stealing problem of intellectual properties. This includes design and implementation of watermarking techniques such as basic DCT, DCT with existing Butterworth filter and DCT with modified Butterworth filter. It concluded that PSNR value is highest and MSE value is lowest for DCT Watermarking technique using Modified Butterworth filter.
\end{abstract}

\section{Introduction}

Watermarking is a technique that used to hide data or identifying information within digital multimedia, for example watermarking of such as digital images, though digital video, audio, and documents are routinely identified. Andrew Tirkel and Charles Osborne first introduced watermarking in 1992.[4] The Digital watermarking is becoming popular for adding undetectable identifying marks, such as author or copyright information. Digital watermarks are inside the information so that third parties cannot claim ownership of the information. While some watermarks are visible, most watermarks are invisible.

Previously Lot of work has been done in the field of watermarking using LSB. Authors had done work using second LSB, LSB and Inverse bit; Different bit positions etc. This work shown in this paper proposed Modified Butterworth filter for watermarking. Many researchers used basic LSB algorithm using different techniques, but it was found that Basic LSB has high PSNR and MSE value but has low security, as in this watermark was embedded into single bit of original image.

V.K. Chandna, V.S. Rathore and S. Maheshwari (eds.), ICETEAS 2018 (Kalpa Publications in Engineering, vol. 2), pp. 109-115 
The paper is organized in the following sections are Section 2 presents the proposed work. Demonstration of process watermarking described in section 3. Section 4 presents the experimental results and performance analysis. Section 5 gives the conclusion. Future work gives in the section 6 .

\section{Proposed Work}

Digital watermarking is the act of hiding a message related to a digital signal (i.e. an image, song, and video) within the signal itself. It is a concept closely related to steganography, in that arises many issues like capacity, robustness, transparency, security. In this work it first read the original image and compares the size with different image file formats like TIF file format, JPEG file format, BMP file format, PNG file format. The experimentations are carried out in MATLAB. The Figure 1 shows the DCT with Modified Butterworth Filter.

\subsection{DCT with Modified Butterworth Filter}

Step 1: Read Original Image.

Step 2: Preprocess the Original Image which has to be filtered.

Step 3: Perform Rounding function on preprocessed image.

Step 4: Get cut off frequency.

Step 5: Get filter order.

Step 6: Apply low pass Butterworth Filtering on this preprocessed image \& apply exponential operation to get filtered image.

Step 7: Apply basic DCT algorithm on the image which was obtained in above step.

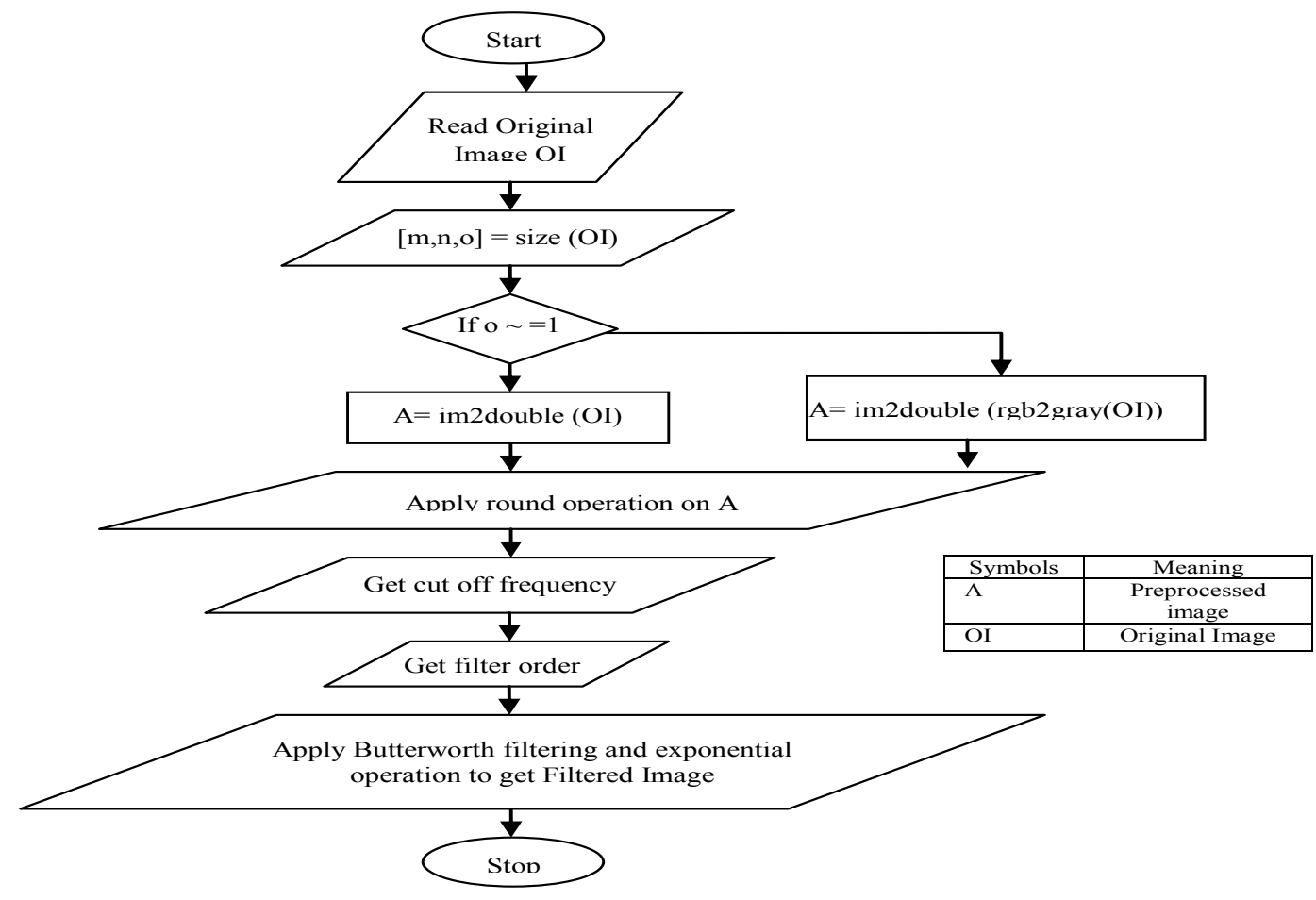

Figure1: Flow chart of DCT with Modified Butterworth 


\section{Demonstration Process of DCT with Modified Butterworth}

\begin{tabular}{|c|c|c|c|c|}
\hline Step Number & Process & Description & Image & Remark \\
\hline 1. & Input & $\begin{array}{l}\text { In this process, an original image has } \\
\text { taken of jpg file format as Input. }\end{array}$ & 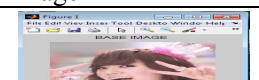 & Girl.jpg \\
\hline 2. & & $\begin{array}{l}\text { Apply Modified Butterworth filter } \\
\text { on original image to get Filtered } \\
\text { Original image }\end{array}$ & 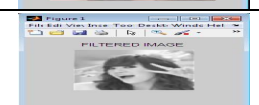 & \\
\hline 3. & & $\begin{array}{l}\text { Input watermark image file i.e. } \\
\text { flowers.jpg }\end{array}$ & 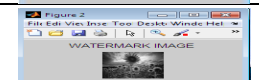 & \\
\hline 4. & & $\begin{array}{l}\text { Apply Modified Butterworth filter } \\
\text { on watermark image to get Filtered } \\
\text { Watermark image }\end{array}$ & & \\
\hline 5. & $\begin{array}{l}\text { Embedding } \\
\text { Process }\end{array}$ & $\begin{array}{l}\text { Embed the Filtered Original image } \\
\text { with Filtered Watermark image } \\
\text { using DCT algorithm }\end{array}$ & 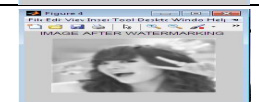 & \\
\hline 6. & $\begin{array}{l}\text { Extraction } \\
\text { Process }\end{array}$ & $\begin{array}{l}\text { Extract watermark image using DCT } \\
\text { algorithm. }\end{array}$ & 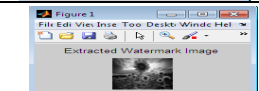 & \\
\hline 7. & & PSNR \& MSE value calculation. & $\begin{array}{l}\text { The mean square error is } 0.18 \text {. } \\
\text { The PSNR = 55.52 } \\
\text { OK }\end{array}$ & \\
\hline
\end{tabular}

This whole process is explained for 1 group and similarly it is analyzed for total of 7 groups. These are shown in table 2.

\begin{tabular}{|c|c|c|c|}
\hline S.No. & Group No. & Original Image & Watermark Image \\
\hline 1. & Group 1 & girl.jpg & $\begin{array}{l}\text { हen: } \\
\text { flowers.jpg }\end{array}$ \\
\hline 2. & Group 2 & car.png & \\
\hline 3. & Group 3 & Guitar.png & \\
\hline 4. & Group 4 & Canoe.tif & \\
\hline 5. & Group 5 & Autumn.tif & Cameraman.tif \\
\hline 6. & Group 6 & $\begin{array}{c}\frac{1}{1} \\
\text { Land.bmp }\end{array}$ & $\begin{array}{c} \\
\text { Forest.bmp } \\
\end{array}$ \\
\hline 7. & Group 7 & 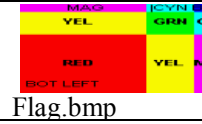 & 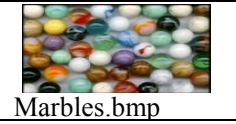 \\
\hline
\end{tabular}

Table 2: Different Original and Watermark images used for experimentation 


\section{Experimental Results \& Performance Analysis}

\subsection{Performance Parameter:}

5.1.1 Peak Signal to Noise Ratio (PSNR): PSNR represents a measure of the peak error. This ratio is often used as a quality measurement between the original and a compressed image.

$$
\begin{aligned}
\text { PSNR } & =10 * \log 10 \frac{\left(M A X_{1}^{2}\right)}{M S E} \\
& =20 * \log 10 \frac{\left(M A X_{1}\right)}{\sqrt{ } M S E}
\end{aligned}
$$

Where, MAX is the maximum possible pixel value of the image

5.1.2 Mean Square Error (MSE): The MSE represents the cumulative squared error between the compressed and the original image. The lower the value of MSE the lower the error.MSE is calculated using the following equation.

$$
M S E=\frac{1}{m * n} \sum_{i=0}^{m-1} \sum_{j=0}^{n-1}[I(i, j)-K(i, j)]^{2}
$$

Where, $\mathrm{m}$ is number of rows, $\mathrm{n}$ is number of columns, I is Original Image, $\mathrm{K}$ is reconstructed Image.

Performance analyses with three different algorithms, which are as follows.

Basic DCT

DCT with Existing Butterworth filter

DCT with Modified Butterworth filter

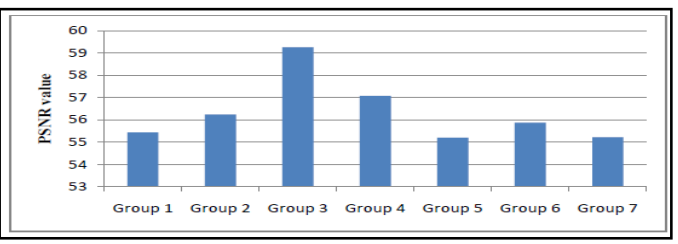

Figure 2: PSNR of DCT based Watermarking Technique on different Image File formats

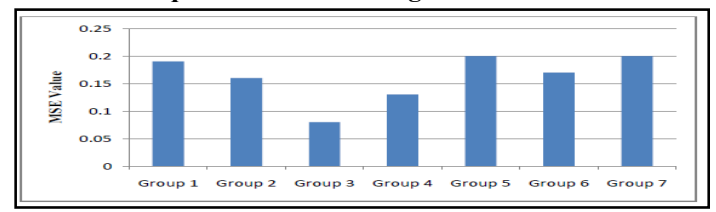

.Figure 3: MSE value of DCT based Watermarking Technique on different Image File formats

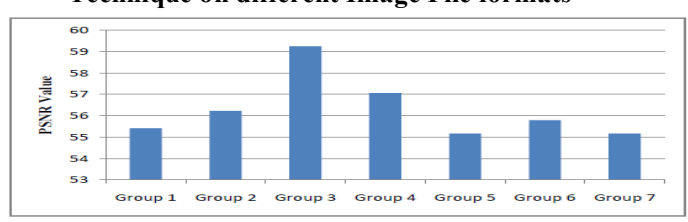

Figure 4: PSNR value of DCT with Existing Butterworth filter on different Image File formats

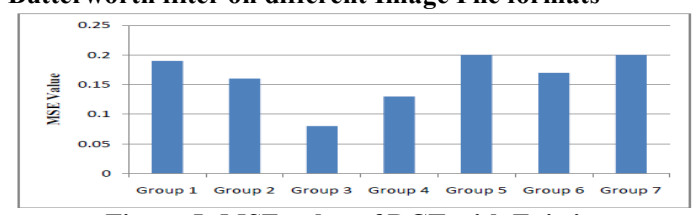

Figure 5: MSE value of DCT with Existing Butterworth filter on different Image File formats
By analyzing Figure 2, it is seen that PSNR value for Group 3 (which is a combination of guitar.png as original image \& tree.png as watermark image) is highest and for Group 5 (which is a combination of autumn.tif as original image \& cameraman.tif as watermark image) is the lowest

By analyzing Figure 3, it is seen that MSE value for Group 3 (which is a combination of guitar.png as original image \& tree.png as watermark image) is lowest and for Group 5 (which is a combination of autumn.tif as original image \& cameraman.tif as watermark image) and Group 7 are same $\&$ highest

By analyzing Figure 4, it is seen that PSNR value for Group 3 (which is a combination of guitar.png as original image \& tree.png as watermark image) is highest and for Group 5 (which is a combination of autumn.tif as original image \& cameraman.tif as watermark image) and Group 7 are same \& lowest.

By analyzing Figure 5, it is seen that MSE value for Group 3 (which is a combination of guitar.png as original image \& tree.png as watermark image) is lowest and for Group 5 (which is a combination of autumn.tif as original image \& cameraman.tif as watermark image) and Group 7 are same $\&$ highest 


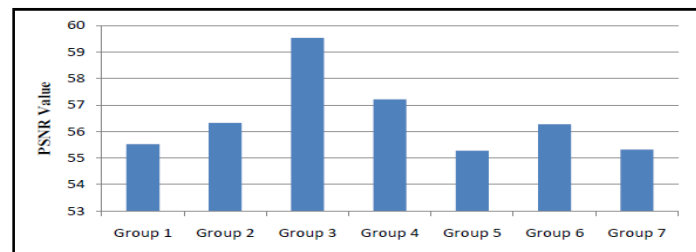

Figure 6: PSNR value of DCT with Modified Butterworth filter on different Image File formats

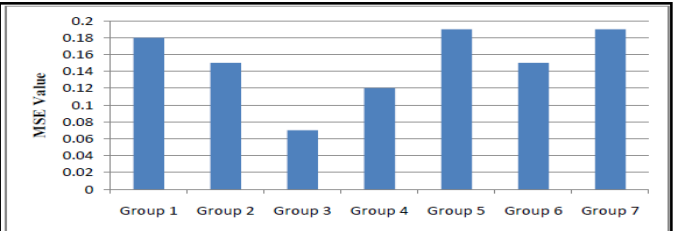

Figure 7: MSE value of DCT with Modified Butterworth filter on different Image File formats
By analyzing Figure 6, it is seen that PSNR value for Group 3 (which is a combination of guitar.png as original image \& tree.png as watermark image) is highest and for Group 5 (which is a combination of autumn.tif as original image \& cameraman.tif as watermark image) is lowest

By analyzing Figure 7, it is seen that MSE value for Group 3 (which is a combination of guitar.png as original image \& tree.png as watermark image) is lowest and for Group 5 (which is a combination of autumn.tif as original image \& cameraman.tif as watermark image) and Group 7 (which is a combination of flag.bmp as original image \& marbles.bmp as watermark image) are same \& highest.

Table 3 shows the performance analysis of basic DCT based Watermarking Technique, DCT with Existing Butterworth filter, and DCT with Modified Butterworth filter on different image file formats in terms of PSNR \& MSE values. Group 1 to 7 represents combination of corresponding original image and watermark image. It is also shows the percentage increment in PSNR \& MSE value of different images of modified Butterworth filter to Existing Butterworth filter

\begin{tabular}{|c|c|c|c|c|c|c|c|c|c|c|c|}
\hline \multirow[t]{2}{*}{$\begin{array}{l}\text { S. } \\
\text { N } \\
\text { o. }\end{array}$} & \multirow{2}{*}{$\begin{array}{l}\text { Groups } \\
\text { (Original } \\
\text { Image+ } \\
\text { watermar } \\
\mathrm{k} \text { Image) }\end{array}$} & \multirow[t]{2}{*}{$\begin{array}{l}\text { Original } \\
\text { Image }\end{array}$} & \multirow[t]{2}{*}{$\begin{array}{l}\text { Watermark } \\
\text { Image }\end{array}$} & \multicolumn{2}{|c|}{$\begin{array}{c}\text { DCT Based } \\
\text { Watermarking }\end{array}$} & \multicolumn{2}{|c|}{$\begin{array}{l}\text { DCT with } \\
\text { Existing } \\
\text { Butterworth }\end{array}$} & \multicolumn{2}{|c|}{$\begin{array}{l}\text { DCT with } \\
\text { Modified } \\
\text { Butterworth }\end{array}$} & \multicolumn{2}{|c|}{$\begin{array}{c}\text { Percentage } \\
\text { increment } \\
\text { from previous } \\
\text { of }\end{array}$} \\
\hline & & & & $\begin{array}{l}\text { PSNR } \\
\text { value }\end{array}$ & $\begin{array}{l}\text { MSE } \\
\text { value }\end{array}$ & $\begin{array}{l}\text { PSNR } \\
\text { value }\end{array}$ & $\begin{array}{l}\text { MSE } \\
\text { value }\end{array}$ & $\begin{array}{l}\text { PSNR } \\
\text { value }\end{array}$ & $\begin{array}{l}\text { MSE } \\
\text { value }\end{array}$ & $\begin{array}{l}\text { PSNR } \\
\text { value }\end{array}$ & $\begin{array}{l}\text { MS } \\
\text { E } \\
\text { valu } \\
\mathrm{e}\end{array}$ \\
\hline 1. & Group 1 & girl.jpg & flowe & 55.43 & 0.19 & 55.41 & 0.19 & 55.52 & 0.18 & 0.20 & 5.26 \\
\hline 2. & Group 2 & car.png & kiwi.png & 56.24 & 0.16 & 56.22 & 0.16 & 56.32 & 0.15 & 0.18 & 6.25 \\
\hline 3. & Group 3 & $\begin{array}{l}\text { Guitar.pn } \\
\mathrm{g}\end{array}$ & Tree.png & 59.26 & 0.08 & 59.24 & 0.08 & 59.53 & 0.07 & 0.49 & 12.5 \\
\hline 4. & Group 4 & Canoe.tif & Scene.tif & 57.07 & 0.13 & 57.06 & 0.13 & 57.21 & 0.12 & 0.26 & 7.69 \\
\hline 5. & Group 5 & $\begin{array}{l}\text { Autumn.t } \\
\text { if }\end{array}$ & $\begin{array}{l}\text { Cameraman } \\
\text { tif }\end{array}$ & 55.20 & 0.20 & 55.17 & 0.20 & 55.27 & 0.19 & 0.18 & 5.00 \\
\hline 6. & Group 6 & $\begin{array}{l}\text { Land.bm } \\
\mathrm{p}\end{array}$ & $\begin{array}{l}\text { Marbles.bm } \\
\text { p }\end{array}$ & 55.87 & 0.17 & 55.79 & 0.17 & 56.27 & 0.15 & 0.86 & $\begin{array}{l}11.7 \\
6\end{array}$ \\
\hline 7. & Group 7 & Flag.bmp & Forest.bmp & 55.22 & 0.20 & 55.17 & 0.20 & 55.32 & 0.19 & 0.27 & 5.00 \\
\hline
\end{tabular}

Table3. Performance Analysis of DCT based Watermarking Technique on different Image File formats

\section{Conclusion}

Watermarking can resolve the stealing problem of intellectual properties. The main objective of this paper was to design and implement Modified Butterworth filter for improvement of image quality in watermarking. Two performance parameters (PSNR \& MSE) were used for analyzing the proposed approach. The experimental analysis was carried out by implementing Basic DCT algorithm, DCT algorithm with existing Butterworth filter and DCT algorithm with Modified Butterworth filter for five different file formats of original image and watermark image The experimental results show that the PSNR value is highest and the MSE value is lowest for png file format in comparison to other file 
formats. It is also analyzed that no more changes occur in the PSNR value of the images of different file format but the MSE value changes up to $12.50 \%$. It is found that PSNR value is highest and MSE value is lowest for all images using DCT Watermarking Technique with Modified Butterworth Filter.

\section{Future Work}

The works planned for the future are, A hybrid system i.e. a collection of more than one filter can used for further improvement of results. The proposed approach can tested against security attacks.

\section{References}

Afroja Akter, Nur-E-Tajnina, Ullah M.A., "Digital image watermarking based on DWT-DCT: Evaluate for a new embedding algorithm," International Conference on Informatics, Electronics \& Vision (ICIEV), 2014, pp.1, 6, 23-24 May 2014

Chau-Jern Cheng; Wen-Jyi Hwang; Han-Yi Zeng; Yu-Chih Lin, "A Fragile Watermarking Algorithm for Hologram Authentication," Journal of Display Technology, vol.10, no.4, pp.263,271, April 2014

Charkari, N.M.; Chahooki, M.A.Z., "A Robust High Capacity Watermarking Based on DCT and Spread Spectrum," IEEE International Symposium on

Signal Processing and Information Technology, 2007, pp.194, 197, 15-18 Dec. 2007

Chavan, S.; Shah, R.; Poojary, R.; Jose, J.; George, G., "A Novel Robust Colour Watermarking Scheme for Colour Watermark Images in Frequency Domain," International Conference on Advances in Recent Technologies in Communication and Computing (ARTCom), 2010, pp.96,100, Oct. 2010

Daxing Zhang, Zhigeng Pan, Haihua Li, "A novel watermarking algorithm in DCT domain to authenticate image content," IEEE International Conference on Intelligent Computing and Intelligent Systems, 2009. ICIS 2009, vol.3, pp.608, 611, Nov. 2009

Deb, K.; Al-Seraj, M.S.; Hoque, M.M.; Sarkar, M.I.H., "Combined DWT-DCT based digital image watermarking technique for copyright protection," International Conference on Electrical \& Computer Engineering (ICECE), 2012, pp.458, 461, Dec. 2012

Deepshikha Chopra, Preeti Gupta, Gaur Sanjay B.C., Anil Gupta, "Lsb Based Digital Image Watermarking For Gray Scale Image," IOSR Journal of Computer Engineering, 2012. IOSRJCE 2012, vol.6, pp. 36, 41, Oct. 2012

Gonge, S.S.; Ghatol, A.A., "Combined DWT-DCT digital Watermarking Technique Software Used for CTS of Bank," International Conference on Issues and Challenges in Intelligent Computing Techniques (ICICT), 2014, pp.776, 783, Feb. 2014

Gurpreet Kaur, Kamaljeet Kaur, "Image Watermarking Using LSB (Least Significant Bit)," International Journal of Advanced Research in Computer Science and Software Engineering, 2013. IJARCSE 2013, pp. 858-861, April 2013

Irfan; Nazori Agani, "Embedding and Extracting Technique for Implementing Image Watermarking Based on DCT (Discrete Cosine Transform)", International Conference on Information Systems, 2013. ISICO2013. pp. 2, 4, Dec. 2013

Juan L. Mateo; Antonio Fernandez Caballero, "Finding out general tendencies in speckle noise reduction in ultrasound images", Journal of Expert Systems with Applications 2009, vol. 36, pp. 7786, 7797, 2009

Manpreet Kaur ;Sonika Jindal ;Sunny Behal, "A study of digital image watermarking", International Journal of Research in Engineering \& Applied Sciences, 2012. IJREAS 2012, vol.2, pp. 126, 136, February 2012

Mehan, V.; Dhir, R.; Brar, Y.S., "Joint watermarking and fingerprinting approach for colored digital images in double DCT domain," IEEE International Conference on Signal Processing, Computing and Control (ISPCC), 2013, pp.1,6, Sept. 2013 
Mehdi Hussain; Mureed Hussain, "A Survey of Image Steganography Techniques", International Journal of Advanced Science and Technology, 2013.IJASAT 2013, vol. 54, pp. 113, 124 